\title{
Latent magmatism in non-volcanic areas in South Korea
}

\author{
HEEJUN KIM ${ }^{1}$, HYUNWOO LEE ${ }^{1}$, JUNGPYO HONG ${ }^{1}$, \\ JUNG-HUN SONG ${ }^{1}$, NAOTO TAKAHATA ${ }^{2}$ AND YUJI \\ $\mathrm{SANO}^{3}$
}

${ }^{1}$ Seoul National University

${ }^{2}$ University of Tokyo

${ }^{3}$ Kochi University

Presenting Author: sooneeujuro@snu.ac.kr

Since active volcanism had ceased for several Millenium, the Korean peninsula has been regarded as a non-volcanic setting. However, the distinct low-velocity zones were reported beneath some parts of the Korean peninsula [1], suggesting the presence of melt. Based on new results of noble gas analysis and previously reported geophysical data, here we propose the possible occurrence of magmatism beneath the Korean peninsula.

According to the $\mathrm{N}_{2}$-Ar-He relationship, all samples from the study area show a two-component mixing relationship between the atmospheric and MORB/crust components, with the absence of subducted slab signals. $\mathrm{N}_{2}$ and $\mathrm{CO}_{2}$ are main components. Wide ranges of $\delta^{15} \mathrm{~N}-\mathrm{N}_{2}\left(-8.0\right.$ to $3.3 \%$ ) and $\delta^{13} \mathrm{C}-\mathrm{CO}_{2}(-20.2$ to $-3.7 \%$ ) indicate that $\mathrm{N}_{2}$ and $\mathrm{CO}_{2}$ are derived from both organic substances in the sedimentary layer and the mantle-derived components [2, 3]. Similarly, ${ }^{3} \mathrm{He} /{ }^{4} \mathrm{He}$ ratios $(0.12 \mathrm{Ra}$ to $6.17 \mathrm{Ra})$ represent that various degrees of mantle-derived helium contributed to this area. The negative correlation between the $\mathrm{S}$ wave velocity anomaly and ${ }^{3} \mathrm{He} /{ }^{4} \mathrm{He}$ ratios appears to imply that the presence of melt and volatiles has lowered the seismic wave velocity, reflected by elevated helium isotope ratios [4].

In addition, the computed ${ }^{3} \mathrm{He}$ fluxes are comparable to the global major fault-controlled hydrothermal systems [5]. The Korean gas samples show that mantle and crustal ${ }^{4} \mathrm{He}$ fluxes are similar to global volcanic regions rather than the tectonic areas [6]. Therefore, combining geochemical results and geophysical information suggests that there could be latent magmatism beneath the non-volcanic Korean peninsula.

[1] Song et al. (2020) Gondwana Res. 81, 475-489. [2] Sano \& Marty (1995) Chem. Geol. 119, 265-274. [3] Sano et al. (2001) Chem. Geol. 171, 263-271. [4] Karlstrom et al. (2013) Geology. 41, 495-498. [5] Kulongoski et al. (2013) Chem. Geol. 339, 92102. [6] Lee et al. (2017) J. Volcanol. Geotherm. Res. 346, 118133. 